\title{
Peroxisome proliferator-activated receptor expression is reduced in skeletal muscle in COPD
}

\author{
A.H. Remels*, P. Schrauwen", R. Broekhuizen*, J. Willems*, S. Kersten", \\ H.R. Gosker* and A.M. Schols*
}

ABSTRACT: Chronic obstructive pulmonary disease (COPD) is a multiorgan systemic disease. The systemic features are skeletal muscle weakness and cachexia, the latter being associated with systemic inflammation. The exact mechanisms underlying skeletal muscle dysfunction in COPD remain obscure. Recent evidence suggests involvement of the peroxisome proliferatoractivated receptors (PPARs) and PPAR- $\gamma$ coactivator (PGC)-1 $\alpha$ in regulation of skeletal muscle morphology and metabolism, and mitochondrial transcription factor A (TFAM) has been implicated in the process of mitochondrial biogenesis. The aim of the present exploratory study was, therefore, to compare these factors in the skeletal muscle of nine healthy control subjects and 14 COPD patients stratified by cachexia.

PPAR- $\gamma$, PPAR- $\delta$ and TFAM were measured at the mRNA and protein level by real-time quantitative PCR and Western blotting, respectively. PPAR- $\alpha$ and PGC-1 $\alpha$ were meansured at the mRNA level.

PPAR- $\delta$ and TFAM protein content, as well as PGC-1 $\alpha$ mRNA levels, were decreased in the skeletal muscle of COPD patients compared with healthy controls. The cachectic COPD subgroup was further characterised by decreased PPAR- $\alpha$ mRNA expression and decreased TFAM protein and mRNA levels compared with noncachectic COPD patients. In addition, PPAR- $\alpha$ mRNA levels in skeletal muscle correlated negatively with inflammatory markers in plasma.

Therefore, a disturbed expression of these regulatory factors may well underlie the disturbed skeletal muscle functioning in chronic obstructive pulmonary disease.

KEYWORDS: Chronic obstructive pulmonary disease, mitochondrial transcription factor A, peroxisome proliferator-activated receptors, peroxisome proliferator-activated receptor- $\gamma$ coactivator-1 $\alpha$, skeletal muscle oxidative capacity

keletal muscle dysfunction has become a recognised hallmark of chronic obstructive pulmonary disease (COPD). Although it is obvious that impaired lung function inevitably leads to reduced exercise tolerance in this disorder, muscle dysfunction is probably an even stronger determinant of exercise capacity, particularly in moderate-to-severe COPD [1]. Moreover, it has been convincingly shown that muscle wasting is a strong predictor of mortality risk in COPD, independent of the degree of airflow limitation [2]. Since current bronchodilator and anti-inflammatory medication primarily aimed at improving lung function is rather ineffective in reversing exercise intolerance, skeletal muscle

For editorial comments see page 191. function may be an interesting alternative target for novel therapies. Skeletal muscle dysfunction in COPD is characterised by the loss of muscle strength and endurance. The loss of muscle endurance is associated with a type $\mathrm{I} \rightarrow \mathrm{IIa} \rightarrow \mathrm{IIx}$ fibre-type shift, leading to decreased oxidative capacity of the muscle [3]. The loss of muscle strength is largely explained by the loss of muscle mass due to cachexia, which is commonly observed in moderate-to-severe COPD patients [4].

Other abnormalities pointing towards intrinsic muscle abnormalities in COPD pathogenesis are decreased content of substrates, such as specific amino acids, increased oxidative stress and decreased levels of uncoupling protein (UCP) 3, a mitochondrial protein that serves as a putative protector against lipid-induced mitochondrial

\section{AFFILIATIONS}

Depts of *Respiratory Medicine and ${ }^{*}$ Human Biology, University of Maastricht, Maastricht, and "Nutrition, Metabolism and Genomics Group, Wageningen University, Wageningen, The Netherlands.

CORRESPONDENCE

A.H. Remels

Dept of Respiratory Medicine University of Maastricht P.0. Box 5800 6202 AZ Maastricht The Netherlands Fax: 31433875051 E-mail: a.remels@pul.unimaas.nl

Received:

November 062006

Accepted after revision: April 062007

SUPPORT STATEMENT

$\mathrm{H}$. Gosker is supported by European Union (Brussels, Belgium) grant QLK6-CT-2002-02285 and an award from the Netherlands Asthma Foundation (Leusden, the Netherlands; project number 3.2.05.038). P. Schrauwen has been supported by fellowships from the Royal Netherlands Academy of Arts and Sciences (Amsterdam, the Netherlands).

STATEMENT OF INTEREST A statement of interest for A.H. Remels can be found at www.erj.ersjournals.com/misc/ statements.shtml

European Respiratory Journal Print ISSN 0903-1936 Online ISSN 1399-3003 
damage [5-7]. In addition, COPD is also characterised by a chronic systemic low-grade inflammatory status, which has been suggested as a trigger for the loss of muscle mass and muscle weakness $[8,9]$. The exact molecular mechanisms and key mediators involved in the loss of muscle strength and endurance in COPD remain to be identified. The peroxisome proliferator-activated receptors (PPARs), as well as PPAR- $\gamma$ coactivator (PGC)-1 $\alpha$, a strong coactivator of PPAR transcriptional activity, are key regulators of mitochondrial biogenesis and hence of skeletal muscle oxidative capacity [10, 11]. Furthermore, they are potent mediators of a fibre-type shift of type $\mathrm{II} \rightarrow \mathrm{I}$, and have been shown to possess anti-inflammatory properties [12, 13]. Based on these findings, it was hypothesised that expression of PPARs is reduced in the skeletal muscle of COPD patients. Therefore, the aim of the present study was to determine expression of the PPARs and PGC- $1 \alpha$ at the mRNA and protein level in skeletal muscle biopsy specimens from COPD patients, pre-stratified by cachexia, and healthy control subjects.

\section{SUBJECTS AND METHODS}

\section{Subjects}

The study population consisted of Dutch patients with clinically stable Global Initiative for Chronic Obstructive Lung Disease stage II-IV COPD $(n=14)$ and a group of healthy age-matched controls $(n=9)$. All patients suffered from chronic airflow limitation, defined as a measured forced expiratory volume in one second (FEV1) $<70 \%$ of reference values. Patients received standardised maintenance respiratory medication that consisted of inhaled bronchodilators, inhaled corticosteroids and, when indicated, theophyllines. The exclusion criteria were concurrent diseases, such as malignancies, gastrointestinal or kidney abnormalities, metabolic or endocrine diseases and inflammatory diseases. Written consent was obtained from all subjects, and the study was approved by the ethical review board of Maastricht University Hospital (Maastricht, the Netherlands).

\section{Pulmonary function}

FEV1 and forced vital capacity were assessed from the flowvolume curve obtained using a spirometer (Masterlab; Jaeger, Würzburg, Germany). Carbon monoxide diffusing capacity of the lung was determined using the single-breath method (Masterlab). Lung function parameters were expressed as a percentage of reference values. Blood was drawn from the brachial artery in order to analyse arterial oxygen and carbon dioxide tension using a blood gas analyser (ABL 330; Radiometer, Copenhagen, Denmark).

\section{Blood sampling and tumour necrosis factor- $\alpha$ ELISA}

Fasting blood was collected in evacuated blood collection tubes containing ethylenediamine tetra-acetic acid (EDTA; Vacutainer System; Becton Dickinson, Plymouth, UK) in the early morning (08:00-10:00 h). After centrifuging twice for $10 \mathrm{~min}$ at $1,000 \times g$ at $4{ }^{\circ} \mathrm{C}$ within $2 \mathrm{~h}$ of collection, plasma samples were stored at $-80^{\circ} \mathrm{C}$ until analysis. Tumour necrosis factor (TNF)- $\alpha$ levels were determined using the Quantikine highsensitivity ELISA (R\&D Systems, Minneapolis, MN, USA), with a lower detection limit of $0.5 \mathrm{pg} \cdot \mathrm{mL}^{-1}$ for total TNF- $\alpha$. Levels of soluble 55-kDa TNF receptor (sTNF-R55) and
sTNF-R75 were measured in duplicate using the ELISA protocol previously described by LEEUWENBERG et al. [14].

\section{Body composition}

Body mass index (BMI) was calculated from weight divided by height in metres squared. Body composition was measured using single-frequency (50 kHz) bioelectrical impedance analysis (BIA; Xitron Technologies, San Diego, CA, USA) with subjects in the supine position. The fat-free mass (FFM) of patients was calculated using the disease-specific equation proposed by ScHOLS et al. [15] and described by STEINER et al. [16]. FFM index (FFMI) and fat mass (FM) index were calculated from FFM or FM divided by height in metres squared. Cachexia was defined as a BMI $\leqslant 21 \mathrm{~kg} \cdot \mathrm{m}^{-2}$ and FFMI $\leqslant 16 \mathrm{~kg} \cdot \mathrm{m}^{-2}$ in male patients or $\leqslant 15 \mathrm{~kg} \cdot \mathrm{m}^{-2}$ in female patients.

\section{Collection and processing of muscle tissue}

Post-absorptive muscle biopsy specimens from the lateral part of the quadriceps femoris were obtained under local anaesthesia using the needle biopsy technique. The specimens were immediately snap-frozen in liquid nitrogen and stored at $-80^{\circ} \mathrm{C}$ until use.

\section{Muscle oxidative phenotype}

A 5\% (weight/volume) homogenate was prepared by dispersion (Polytron ${ }_{\circledR}$ PT 1600 E; Kinematica, Lucerne, Switzerland) followed by sonication (Branson 2210; Branson Ultrasonics Corporation, Danbury, CT, USA) of the tissue in $250 \mathrm{mM}$ sucrose, $2 \mathrm{mM}$ EDTA, $10 \mathrm{mM}$ tris(hydroxymethyl)aminomethane (Tris; $\mathrm{pH} 7.4$ ) for $1 \mathrm{~min}$. The samples were centrifuged for $10 \mathrm{~min}$ at $10,000 \times g$ at $4^{\circ} \mathrm{C}$. The supernatant was used for determination of citrate synthase activity, as described by GOSKER et al. [17]. The remaining pellet was resuspended in three volumes of ice-cold extraction buffer $(100 \mathrm{mM}$ $\mathrm{Na}_{4} \mathrm{O}_{7} \mathrm{P}_{2} \cdot 10 \mathrm{H}_{2} \mathrm{O}$ (pH8.5), $5 \mathrm{mM}$ EDTA, $1 \mathrm{mM}$ dithiothreitol), incubated on ice for $30 \mathrm{~min}$ and centrifuged for $10 \mathrm{~min}$ at $10,000 \times g$ at $4{ }^{\circ} \mathrm{C}$. The supernatant was used for myosin heavy chain (MHC) isoform analysis. Electrophoresis gels were run for $22 \mathrm{~h}$ using a Protean II xi Cell system (Bio-Rad, Veenendaal, the Netherlands) at $20 \mathrm{~mA}$, with voltage increasing to a maximum of $350 \mathrm{~V}$. Approximately $1.0 \mu \mathrm{g}$ protein was loaded per lane. The gels were silver-stained (Silver Stain Plus Kit; Bio-Rad, Veenendaal, the Netherlands), scanned and photographed using a scanning densitometer (Fluor-S ${ }^{(i m}$ MultiImager; Bio-Rad), after which the protein bands were quantified using Quantity One software (Bio-Rad). Levels of I, IIa and IIx MHC isoforms were expressed relative to each other.

\section{Real-time quantitative PCR}

Total RNA was extracted using the acid guanidium thiocyanate-phenol-chloroform extraction method (Ambion, Foster City, CA, USA). RNA concentration was determined using a spectrophotometer and quality was verified by agarose gel electrophoresis. RNA ( $2 \mu \mathrm{g}$ per sample) was reverse transcribed to give complementary DNA (cDNA) according to the manufacturer's instructions (iScript RT kit; Bio-Rad, Hercules, CA, USA). cDNA was PCR amplified using Platinum Taq DNA polymerase (Invitrogen, Breda, the Netherlands) on a Bio-Rad iCycler apparatus (Bio-Rad, USA). The primers were designed to generate a PCR amplification product of 100-150 bp. The 
specificity of the amplification was verified by melt curve analysis and evaluation of efficiency of PCR amplification. Transcript levels of the constitutive housekeeping gene product 36B4 were quantitatively measured in each sample in order to control for sample-to-sample differences in RNA concentration. Gene expression was quantified and expressed in arbitrary units (AU).

\section{Western blot analysis of protein expression}

PPAR- $\delta$ and mitochondrial transcription factor A (TFAM) abundance were evaluated by Western blotting. Muscle biopsy specimens were homogenised in PBS containing phenylmethylsulphonyl fluoride $(0.4 \mathrm{mM})$ and EDTA $(1 \mathrm{mM})$ and sonicated twice for $10 \mathrm{~s}$ at $12 \mu \mathrm{m}$ and once for $5 \mathrm{~s}$ at $20 \mu \mathrm{m}$. Subsequently, the samples were diluted 2:1 in sample buffer containing 2-mercaptoethanol and sodium dodecylsulphate and boiled for $5 \mathrm{~min}$. Equal amounts of protein were loaded on to a 10 and $12 \%$ (PPAR- $\delta$ and TFAM, respectively) discontinuous denaturating polyacrylamide gel, and electrophoresis was performed using a Mini-PROTEAN 3 Electrophoresis Cell system (Bio-Rad, USA). The primary antibodies, used according to the manufacturer's manual, included anti-PPAR- $\delta$ diluted 1:5,000 and anti-TFAM diluted 1:10,000 (both from Santa Cruz, Santa Cruz, CA, USA). The secondary antibodies $(1: 10,000)$ were rabbit anti-goat peroxidase and pig anti-rabbit peroxidase (both from Dako Cytomation, Glostrup, Denmark). Detection was performed using SuperSignal West Dura Extended Duration Substrate (Pierce Boston Technology Centre, Woburn, MA, USA) on a CL-Xposure Film (Pierce Boston Technology Centre). Densitometric quantification was performed using Image Master VDS (Amersham Pharmacia Biotech, Uppsala, Sweden). A standard sample was included in every blot in order to correct for blot-to-blot variation. PPAR- $\delta$ and TFAM content were both expressed in AU.

\section{Statistical analysis}

Data were analysed according to the guidelines of ALtMAn et al. [18], using an unpaired t-test (corrected for unequal variances as appropriate), one-way ANOVA (with an unpaired t-test as the post hoc test) or Pearson's correlation test, and with nonparametric tests when appropriate. Data are presented as mean \pm SD. A two-tailed p-value of $<0.05$ was considered significant.

\section{RESULTS}

\section{Subject characteristics}

The characteristics of the patients and control subjects are summarised in table 1 . No significant differences in age and cumulative cigarette consumption (in pack-yrs) were observed between patients and controls, providing a correction for smoking behaviour between groups. Also, no significant differences were observed between the lung function of cachectic COPD patients and that of noncachectic patients.

\section{Muscle fibre-type composition}

The proportion of MHC type I tended to be lower in COPD patients than in control subjects $(24.6 \pm 7.1$ versus $30.6 \pm 6.7 \%$; $\mathrm{p}=0.114$ ). There were no significant differences in the proportions of MHC type IIa between patients and healthy controls. The proportions of MHC type IIx was higher in patients than in controls ( $30.4 \pm 5.7$ versus $19.4 \pm 10.9 \% ; \mathrm{p}=0.044$; fig. 1$)$. No significant differences in fibre-type composition were observed between cachectic and noncachectic patients.

\section{PPAR- $\alpha$}

There were no significant differences in PPAR- $\alpha$ mRNA expression in skeletal muscle from patients and control subjects. However, a trend of lower PPAR- $\alpha$ mRNA levels in patients than in controls was observed $(1.39 \pm 0.75$ versus $1.87 \pm 0.46 \mathrm{AU} ; \mathrm{p}=0.09$; table 2 ). Interestingly, expression levels of PPAR- $\alpha$ mRNA were $>50 \%$ lower in cachectic COPD patients than in noncachectic patients $(0.87 \pm 0.47$ versus $2.14 \pm 0.69 \mathrm{AU} ; \mathrm{p}=0.008)$ and healthy controls $(1.87 \pm 0.46 \mathrm{AU}$; $\mathrm{p}=0.004$; fig. 2). In addition, PPAR- $\alpha$ mRNA levels in the patient group correlated positively and significantly with $\mathrm{BMI}$ $(\mathrm{r}=0.700 ; \mathrm{p}=0.005)$ and FFMI $(\mathrm{r}=0.593 ; \mathrm{p}=0.025)$. Although several commercially available PPAR- $\alpha$ antibodies were tested, none were of sufficient quality and specificity to detect PPAR- $\alpha$ protein.

\section{PPAR- $\delta$}

There were no significant differences in the level of expression of PPAR- $\delta$ mRNA between patients and healthy control subjects. A trend towards lower PPAR- $\delta$ mRNA levels was observed in skeletal muscle from cachectic versus noncachectic patients $(0.95 \pm 0.33$ versus $1.29 \pm 0.28$ AU; $p=0.085$; table 2$)$. At the protein level, PPAR- $\delta$ content was significantly lower in

\begin{tabular}{|c|c|c|c|}
\hline & \multirow[t]{2}{*}{ Controls } & \multicolumn{2}{|c|}{ COPD } \\
\hline & & Cachectic & Noncachectic \\
\hline$M / F \mathbf{n}$ & $6 / 3$ & $4 / 3$ & $4 / 3$ \\
\hline Age yrs & $65 \pm 4$ & $58 \pm 13$ & $67 \pm 9$ \\
\hline Height $\mathrm{cm}$ & $166.1 \pm 7.6$ & $168.0 \pm 10.5$ & $167.2 \pm 7.2$ \\
\hline \multicolumn{4}{|l|}{ Body composition } \\
\hline Weight kg & $74.7 \pm 10.4$ & $59.0 \pm 8.8^{\#}$ & $72.5 \pm 11.7$ \\
\hline BMl $\mathrm{kg} \cdot \mathrm{m}^{-2}$ & $27.1 \pm 3.7$ & $20.1 \pm 1.3^{\#}$ & $27.0 \pm 3.4$ \\
\hline FFM kg & $50.5 \pm 9.1$ & $43.2 \pm 5.9^{\bullet}$ & $48.8 \pm 8.05$ \\
\hline $\mathrm{FFMI} \mathrm{kg} \cdot \mathrm{m}^{-2}$ & $18.0 \pm 2.3$ & $14.8 \pm 0.7^{\#}$ & $17.3 \pm 2.2$ \\
\hline FM kg & $23.3 \pm 8.1$ & $15.8 \pm 4.1^{\bullet}$ & $23.7 \pm 6.4$ \\
\hline $\mathrm{FMI} \mathrm{kg} \cdot \mathrm{m}^{-2}$ & $8.4 \pm 3.5$ & $5.4 \pm 1.2^{\#}$ & $8.9 \pm 2.2$ \\
\hline \multicolumn{4}{|l|}{ Lung function } \\
\hline FVC \% pred & $100.4 \pm 20.5^{\star *}$ & $74.0 \pm 15.4$ & $79.8 \pm 17.5$ \\
\hline FEV $1 \%$ pred & $117.2 \pm 19.8^{\star *}$ & $38.8 \pm 11.6$ & $41.4 \pm 18.5$ \\
\hline DL,CO \% pred & $83.6 \pm 29.2^{*}$ & $43.3 \pm 18.8$ & $60.9 \pm 29.0$ \\
\hline Smoking pack-yrs & $35 \pm 17$ & $27 \pm 14$ & $35.7 \pm 5$ \\
\hline $\mathrm{Pa}, \mathrm{O}_{2} \mathrm{kPa}$ & $9.7 \pm 0.8$ & $9.0 \pm 1.5$ & $9.4 \pm 1.1$ \\
\hline $\mathrm{Pa}, \mathrm{CO}_{2} \mathrm{kPa}$ & $5.2 \pm 0.4$ & $5.3 \pm 0.7$ & $5.2 \pm 0.9$ \\
\hline
\end{tabular}

Data are presented as mean $\pm \mathrm{SD}$, unless otherwise stated. COPD: chronic obstructive pulmonary disease; $\mathrm{M}$ : male; F: female; BMI: body mass index; FFM: fat-free mass; FFMI: fat-free mass index; FM: fat mass; FMI: fat mass index; FVC: forced vital capacity; \% pred: \% predicted; FEV 1 : forced expiratory volume in one second; $D \mathrm{~L}, \mathrm{CO}$ : diffusing capacity of the lung for carbon monoxide; $\mathrm{Pa}, \mathrm{O}_{2}$ : arterial oxygen tension; $\mathrm{Pa}_{2} \mathrm{CO}_{2}$ : arterial carbon dioxide tension ${ }^{*}: \mathrm{p}<0.01$ versus noncachectic patients; $\because \mathrm{p}<0.05$; *: $\mathrm{p}<0.05$; **: $\mathrm{p}<0.01$ versus COPD patients. 


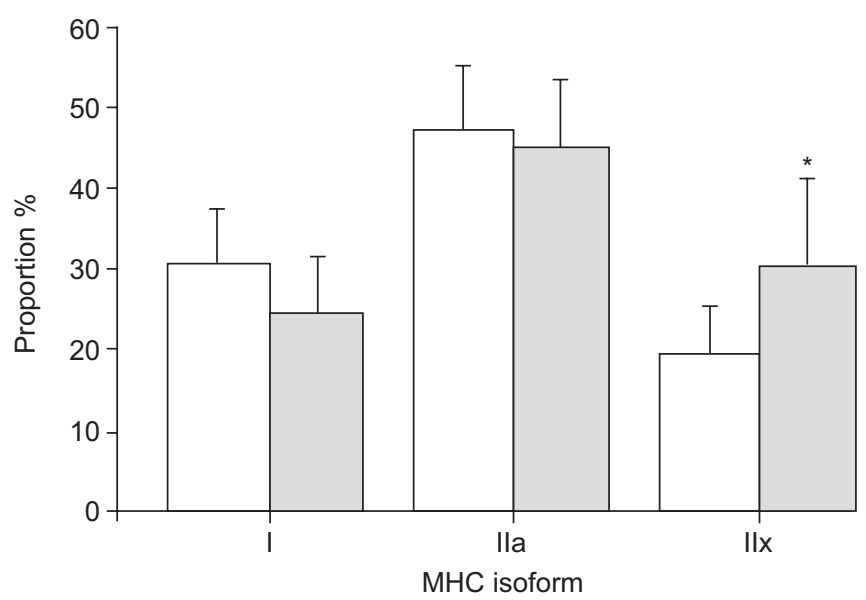

FIGURE 1. Fibre-type distribution in the quadriceps femoris of chronic obstructive pulmonary disease patients $(\square ; n=13)$ and healthy control subjects $(\square ; n=6)$. Data are presented as mean \pm SD. MHC: myosin heavy chain. *: $p<0.05$ versus controls.

skeletal muscle from COPD patients than from healthy control subjects ( $1.67 \pm 0.85$ versus $2.64 \pm 0.95 \mathrm{AU} ; \mathrm{p}=0.037$; fig. $3 \mathrm{a}$ and $\mathrm{b})$. No significant differences in PPAR- $\delta$ content were observed between cachectic and noncachectic patients (fig. 3a).

\section{PPAR- $\gamma$}

PPAR- $\gamma$ mRNA protein levels were too low to be detected in skeletal muscle. PPAR- $\gamma$ could be detected in human adipose tissue (as a positive control), but was below the detection limit in the muscle samples (data not shown).

\section{TFAM}

No significant differences in TFAM mRNA expression levels were found between patients and controls. However, TFAM mRNA levels were significantly lower in cachectic than in noncachectic patients $(0.78 \pm 0.27$ versus $1.21 \pm 0.25 \mathrm{AU} ; \mathrm{p}=0.013)$. In addition, Western blot analysis revealed a significantly lower content of TFAM in skeletal muscle from COPD patients than in that from healthy controls $(0.80 \pm 0.36$ versus $1.20 \pm 0.13 \mathrm{AU}$;

\begin{tabular}{lcccc} 
TABLE 2 & mRNA expression levels in skeletal muscle \\
& Controls & \multicolumn{3}{c}{ COPD } \\
\cline { 3 - 5 } & & Total & Cachectic & Noncachectic \\
\cline { 3 - 5 } & & & & \\
\hline & & & & \\
PPAR- $\boldsymbol{\alpha}$ & $1.87 \pm 0.46$ & $1.39 \pm 0.75$ & $0.87 \pm 0.47^{\star *}$ & $2.14 \pm 0.69$ \\
PPAR- $\boldsymbol{\delta}$ & $1.07 \pm 0.17$ & $1.12 \pm 0.34$ & $0.95 \pm 0.33$ & $1.29 \pm 0.28$ \\
PPAR- $\boldsymbol{\gamma}$ & $\mathrm{ND}$ & $\mathrm{ND}$ & $\mathrm{ND}$ & $\mathrm{ND}$ \\
TFAM & $1.00 \pm 0.27$ & $1.00 \pm 0.34$ & $0.78 \pm 0.27^{*}$ & $1.21 \pm 0.25$ \\
PGC-1 $\boldsymbol{\alpha}$ & $1.38 \pm 0.23$ & $1.00 \pm 0.49^{*}$ & $0.89 \pm 0.43$ & $1.11 \pm 0.56$ \\
\hline
\end{tabular}

Data are presented as mean \pm SD arbitrary units. COPD: chronic obstructive pulmonary disease; PPAR: peroxisome proliferator-activated receptor; TFAM: mitochondrial transcription factor A; PGC: PPAR- $\gamma$ coactivator; ND: nondetectable. ${ }^{*}: p<0.05$; *: $p<0.05$ versus controls; **: $p<0.01$ versus noncachectic patients.

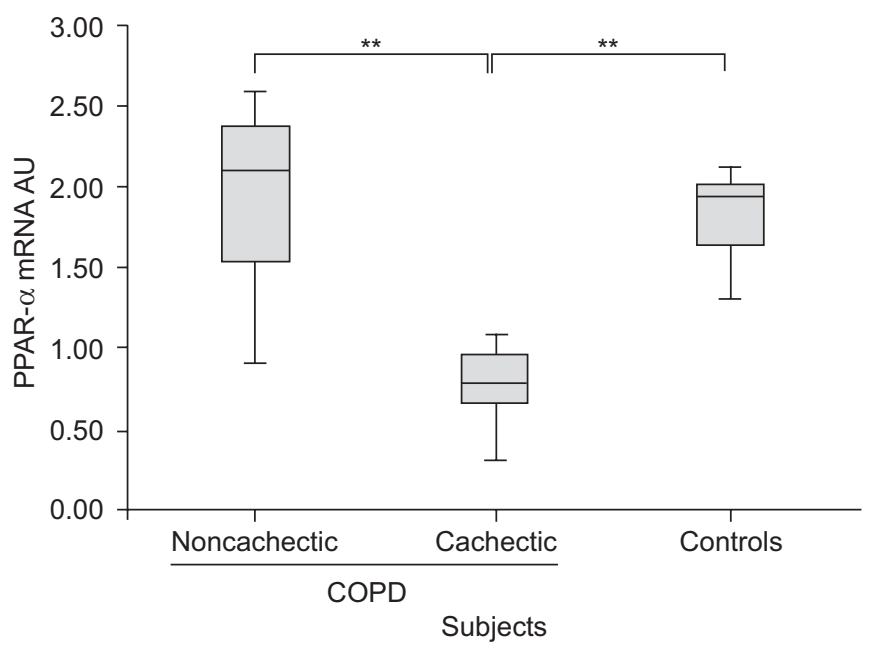

FIGURE 2. Box plot showing expression of peroxisome proliferator-activated receptor (PPAR)- $\alpha$ mRNA in skeletal muscle from cachectic $(n=7)$ and noncachectic $(n=7)$ chronic obstructive pulmonary disease COPD patients and healthy control subjects $(n=9)$, controlled using 36B4 as housekeeping gene. Data are presented as median \pm SD (: interquartile range). AU: arbitrary unit. **: $p<0.01$.

$\mathrm{p}<0.001$ ). Moreover, TFAM protein content was also significantly lower in cachectic than in noncachectic patients $(0.60 \pm 0.23$ versus $0.95 \pm 0.37 \mathrm{AU} ; \mathrm{p}=0.023$; fig. 4$)$.

\section{PGC-1 $\alpha$}

Expression of PGC- $1 \alpha$ mRNA was lower in COPD patients than in healthy controls $(1.00 \pm 0.49$ versus $1.38 \pm 0.23 \mathrm{AU}$; $p=0.044$; fig. 5). There were no differences in PGC- $1 \alpha$ mRNA level between cachectic and noncachectic patients. PGC- $1 \alpha$ protein content could not be assessed due to the lack of commercially available high-quality antibodies.

\section{Correlations}

Correlation analysis was performed to investigate whether PPAR expression levels or protein content were associated with systemic inflammation, muscle oxidative capacity, muscle fibre-type distribution or lung function. Expression levels of PPAR- $\alpha$ mRNA correlated negatively with circulating levels of TNF- $\alpha(r=-0.576 ; p=0.031$; fig. 6$)$. Similar results were found for sTNF-R55 $(r=-0.606 ; p=0.022)$ and sTNF-R75 $(r=-0.546$; $\mathrm{p}=0.044)$. With regard to metabolic markers, PPAR- $\delta$ and PPAR- $\alpha$ mRNA levels in skeletal muscle correlated positively with the oxidative enzyme citrate synthase $(r=0.587 ; p=0.005$, and $\mathrm{r}=0.463 ; \mathrm{p}=0.035$, respectively). In addition, the proportion of MHC type I fibres correlated positively and significantly with skeletal muscle TFAM protein content $(r=0.554$; $p=0.014)$. No correlations were observed between PPAR expression levels and lung function parameters.

\section{DISCUSSION}

COPD is characterised by reduced skeletal muscle function. Muscle oxidative capacity is reduced, which is related to a fibre-type shift from type I oxidative to type IIx glycolytic fibres. In addition, the oxidative capacity within intermediary type IIa fibres is also reduced [19, 20]. As the PPAR transcription factors are involved in the regulation of muscular oxidative capacity, PPAR expression levels were determined in 


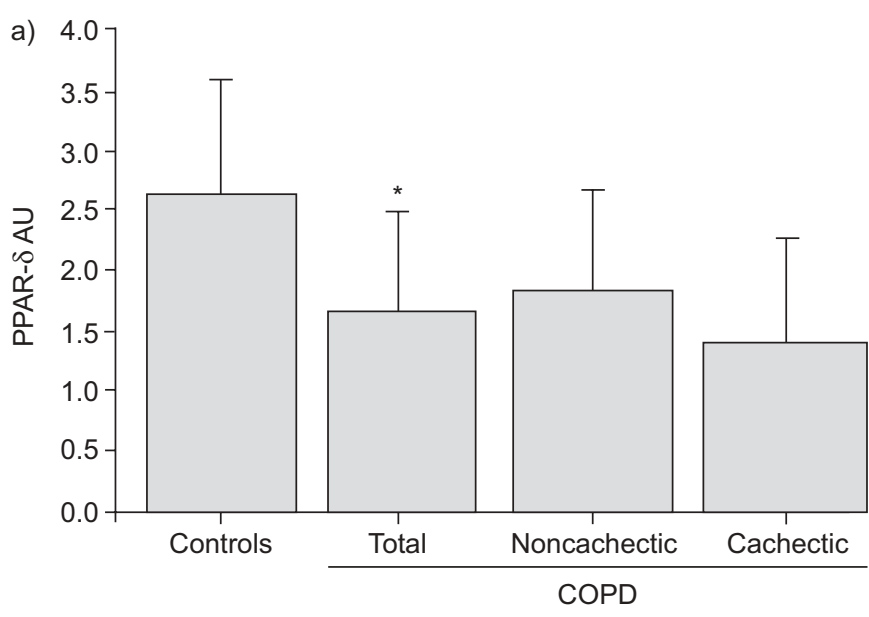

Subjects

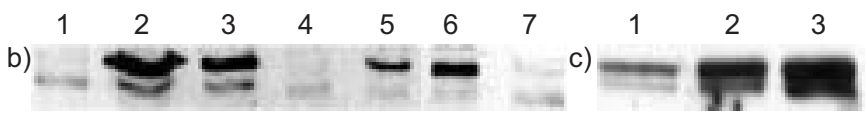

FIGURE 3. a) Expression of peroxisome proliferator-activated receptor (PPAR) $-\delta$ in skeletal muscle from cachectic $(n=7)$ and noncachectic $(n=7)$ chronic obstructive pulmonary disease (COPD) patients and healthy control subjects $(n=9)$. Data are presented as mean $\pm \mathrm{SD}$. AU: arbitrary unit. ${ }^{*}: \mathrm{p}<0.05$ versus controls. b) Representative Western blot analysis of PPAR- $\delta$ (lanes 2 and 3: controls; lanes 4-7: COPD patients). Equal amounts of protein were loaded in each lane and a standard sample (lane 1) was included to correct for blot-to-blot variation. c) The specificity of the antibody directed against human PPAR- $\delta$ was tested by viral transfection of human PPAR- $\delta$ protein into neonatal rat cardiomyocytes (lane 1: 5,000 viral particles $\cdot$ cell $^{-1}$; lane 2: 10,000 viral particles $\cdot$ cell $^{-1}$; lane 3: 25,000 viral particles $\cdot$ cell $^{-1}$ ). An increasing amount of virus resulted in an increasing intensity of both bands of $50 \mathrm{kDa}$ (PPAR- $\delta$ ).

the skeletal muscle of COPD patients. In the present study it is reported for the first time that PPAR- $\delta$ protein content is reduced in the skeletal muscle of COPD patients. Like PPAR- $\alpha$, PPAR $-\delta$ is a strong positive regulator of skeletal muscle oxidative metabolism as it is involved in the regulation of proteins implicated in the uptake, handling and oxidation of fatty acids, as well as other oxidative enzymes [11]. Indeed, in the present study, PPAR- $\delta$ and PPAR- $\alpha$ mRNA levels correlated positively with the activity of the oxidative tricarboxylic acid cycle enzyme citrate synthase, consistent with involvement of these two PPAR subtypes in skeletal muscle oxidative metabolism.

In addition to a decreased PPAR- $\delta$ content, mRNA levels of PGC- $1 \alpha$, a strong PPAR coactivator and key regulator of mitochondrial biogenesis, were also reduced in the skeletal muscle of these patients [21]. It has been shown that PPAR- $\delta$ and PGC- $1 \alpha$ both have the ability to redirect fibre-type distribution in skeletal muscle to a more oxidative phenotype $[11,22,23]$. Given that COPD patients are characterised by an increased amount of type IIx glycolytic fibres, it is tempting to suggest that the reduction in PPAR- $\delta$ and PGC- $1 \alpha$ is causally related to this fibre-type shift. Although no significant correlations were found between PPAR, PGC- $1 \alpha$ and fibretype composition, there was a significant positive correlation between the PGC- $1 \alpha$-regulated TFAM and type I oxidative
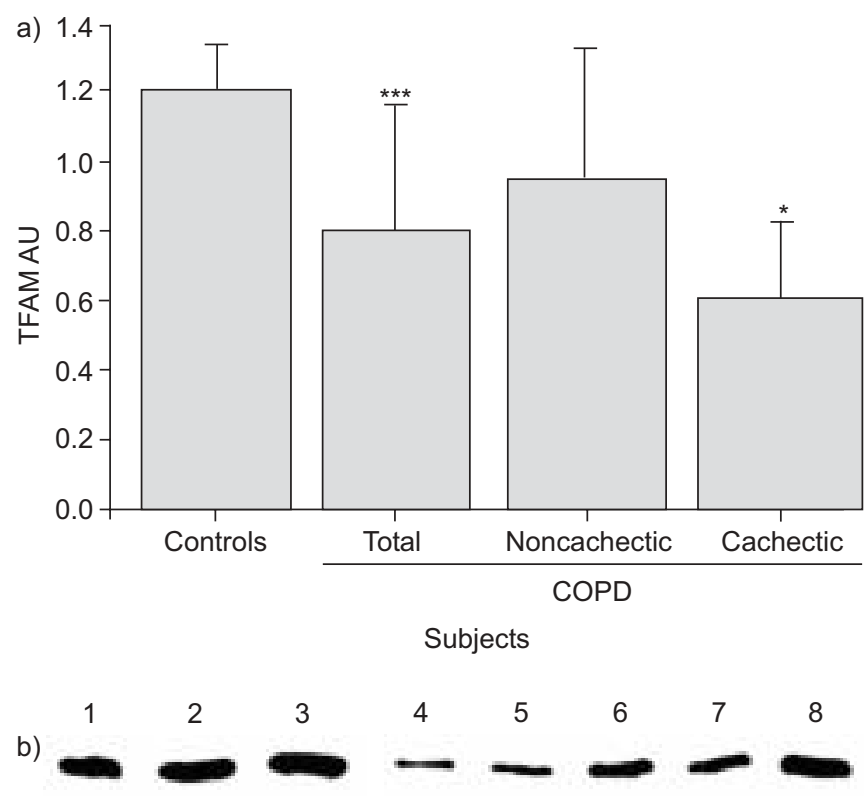

FIGURE 4. a) Mitochondrial transcription factor A (TFAM) protein content of skeletal muscle from cachectic $(n=7)$ and noncachectic $(n=7)$ chronic obstructive pulmonary disease (COPD) patients and healthy control subjects $(n=9)$. Data are presented as mean $\pm \mathrm{SD}$. AU: arbitrary unit. ${ }^{*}: \mathrm{p}<0.05$ versus noncachectic; ${ }^{* *}$ : $p<0.001$ versus controls. b) Representative Western blot analysis of TFAM (lanes 2 and 3: controls; lanes 4-8: COPD patients). Equal amounts of protein were loaded in every lane and a standard sample (lane 1) was included to correct for blot-to-blot variation. A 28-kDa band was identified as TFAM.

fibres. Consistent with involvement of a reduced PPAR content in the reduction in oxidative capacity in COPD is the finding that UCP3 content is reduced in COPD [6]. Several reports have shown that UCP3 is a PPAR-regulated gene [24]. Moreover, SCHRAUWEN et al. [25] reported that administration of rosiglitazone, a potent PPAR- $\gamma$ agonist, restored muscular UCP3 levels in diabetic patients. These observations further strengthen the suggestion that PPARs play a role in skeletal muscle abnormalities, as observed in COPD.

In addition to its regulatory role in skeletal muscle morphology, PGC- $1 \alpha$ is also involved in the regulation of TFAM, which, in turn, controls the expression of mitochondrially encoded genes involved in mitochondrial biogenesis and respiration [26]. Interestingly, in the present study, a lower expression of PGC- $1 \alpha$ mRNA in skeletal muscle from COPD patients was accompanied by a reduced TFAM protein content. Thus reduced levels of PGC- $1 \alpha$ may well be involved in the loss of muscular oxidative capabilities in COPD. Intriguingly, in other disease models, such as congestive heart failure and diabetes mellitus, a decreased oxidative capacity of skeletal muscle is also associated with decreased expression of PGC- $1 \alpha$ mRNA $[27,28]$. Since there was a lack of specific antibodies, it was not possible to verify whether or not PGC- $1 \alpha$ levels were indeed reduced in the skeletal muscle of COPD patients, but this remains an interesting topic for future research.

Although a lower PPAR- $\delta$ and TFAM protein content was observed in the skeletal muscle of COPD patients, no significant differences in the expression levels of PPAR- $\delta$ or TFAM mRNA were observed in skeletal muscle between 


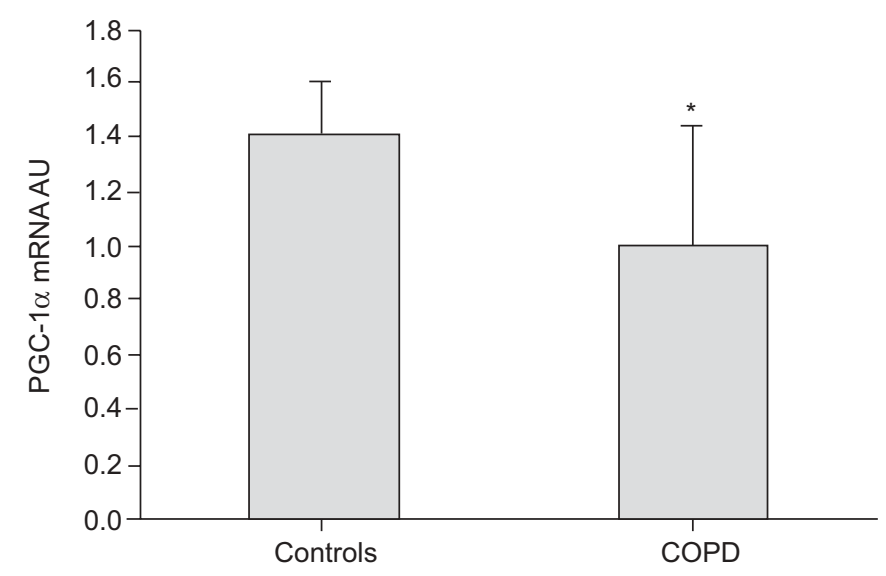

Subjects

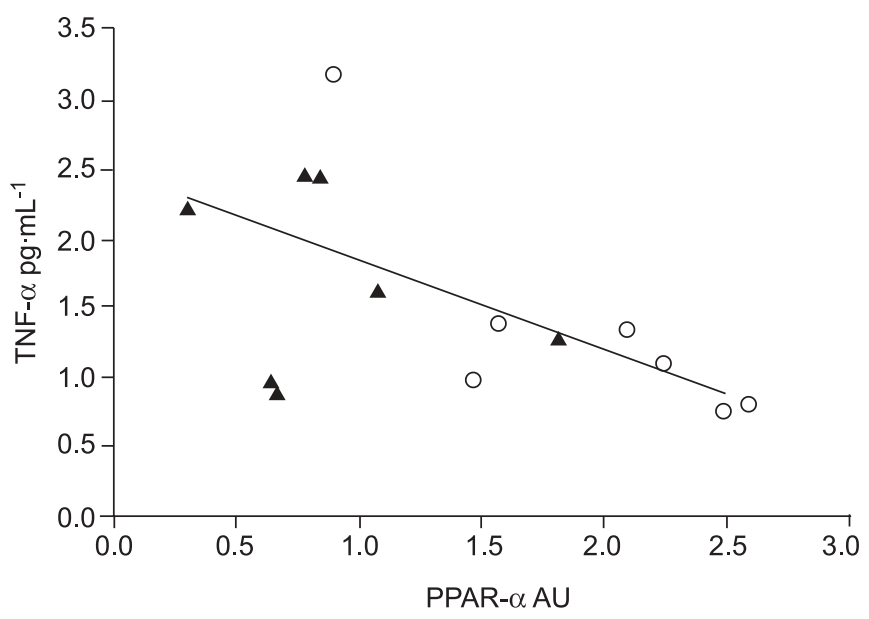

FIGURE 6. Correlation between blood circulatory levels of tumour necrosis factor (TNF)- $\alpha$ and expression levels of peroxisome proliferator-activated receptor (PPAR)- $\alpha$ mRNA in skeletal muscle from chronic obstructive pulmonary disease patients. $\bigcirc$ : noncachectic; $\boldsymbol{\Delta}$ : cachectic. AU: arbitrary unit. $\mathrm{n}=14$.

which is often adopted by COPD patients due to disease-related exercise limitations, could underlie the reduced protein content of PPAR- $\delta$ and reduced PGC- $1 \alpha$ mRNA levels in skeletal muscle, as it has been shown that PPAR- $\delta$ and PGC$1 \alpha$ are strongly upregulated by physical exercise [23, 30-32]. Hypoxia and inflammation, both commonly observed in COPD, may also contribute to the lower PPAR expression levels, as there are several reports that suggest a negative influence of these parameters on PPAR expression levels [33, 34]. The specific contribution of these factors remains unknown, and in vitro approaches should shed more light on the involvement of hypoxia and inflammation in PPAR expression levels and content. Intriguingly, diabetes mellitus and congestive heart failure, diseases characterised by systemic inflammation and increased levels of inactivity, are also characterised by decreased muscular levels of PPAR and/or PGC- $1 \alpha$, suggesting a prominent role for inflammation and physical activity level in controlling PPAR and PGC-1 $\alpha$ levels $[27,28,35]$. As the PPARs, and more specifically PPAR- $\alpha$ and PPAR- $\delta$, are highly implicated in skeletal muscle oxidative metabolism, which is obviously impaired in COPD patients, they could serve as interesting therapeutic targets. Increasing PPAR levels by means of exercise, fatty acid supplementation and/or pharmacological modulation could serve as a potential therapeutic strategy for alleviating exercise intolerance in this disorder.

\section{CONCLUSIONS}

Reduced expression of peroxisome proliferator-activated receptor- $\gamma$ coactivator- $1 \alpha$ mRNA and a lower protein content of peroxisome proliferator-activated receptor- $\delta$ were found in the lower limb skeletal muscle of chronic obstructive pulmonary disease patients compared to healthy controls. In addition, these reductions were accompanied by a decreased content of mitochondrial transcription factor A. These findings imply disturbed regulation of muscular oxidative capacity since peroxisome proliferator-activated receptor- $\delta$, peroxisome proliferator-activated receptor- $\gamma$ coactivator- $1 \alpha$ and mitochondrial transcription factor A are highly implicated in determin- 
ing skeletal muscle oxidative capacity. Therefore, disturbed expression and/or content of these regulatory factors may well underlie the disturbed skeletal muscle functioning in chronic obstructive pulmonary disease. In addition, it is suggested that not only the occurrence of the disease but also the presence of cachexia and chronic inflammation affect peroxisome proliferator-activated receptor mRNA and protein levels. Since the explanation for a lower expression and content of peroxisome proliferator-activated receptors and peroxisome proliferator-activated receptor- $\delta$-related factors in skeletal muscle from chronic obstructive pulmonary disease patients is complex, further investigation is required to unravel the exact mechanisms behind these observations.

\section{REFERENCES}

1 Richardson RS, Leek BT, Gavin TP, et al. Reduced mechanical efficiency in chronic obstructive pulmonary disease but normal peak $V^{\prime} \mathrm{O}_{2}$ with small muscle mass exercise. Am J Respir Crit Care Med 2004; 169: 89-96.

2 Marquis K, Debigare R, Lacasse Y, et al. Midthigh muscle cross-sectional area is a better predictor of mortality than body mass index in patients with chronic obstructive pulmonary disease. Am J Respir Crit Care Med 2002; 166: 809-813.

3 Mador MJ, Bozkanat E. Skeletal muscle dysfunction in chronic obstructive pulmonary disease. Respir Res 2001; 2: 216-224.

4 Gosker HR, van Mameren H, van Dijk PJ, et al. Skeletal muscle fibre-type shifting and metabolic profile in patients with chronic obstructive pulmonary disease. Eur Respir J 2002; 19: 617-625.

5 Langen RC, Korn SH, Wouters EF. ROS in the local and systemic pathogenesis of COPD. Free Radic Biol Med 2003; 35: 226-235.

6 Gosker HR, Schrauwen P, Hesselink MK, et al. Uncoupling protein-3 content is decreased in peripheral skeletal muscle of patients with COPD. Eur Respir J 2003; 22: 88-93.

7 Engelen MP, Schols AM, Does JD, Deutz NE, Wouters EF. Altered glutamate metabolism is associated with reduced muscle glutathione levels in patients with emphysema. Am J Respir Crit Care Med 2000; 161: 98-103.

8 Broekhuizen R, Grimble RF, Howell WM, et al. Pulmonary cachexia, systemic inflammatory profile, and the interleukin 1 $\beta-511$ single nucleotide polymorphism. Am J Clin Nutr 2005; 82: 1059-1064.

9 Di Francia M, Barbier D, Mege JL, Orehek J. Tumor necrosis factor- $\alpha$ levels and weight loss in chronic obstructive pulmonary disease. Am J Respir Crit Care Med 1994; 150: 1453-1455.

10 Koves TR, Li P, An J, et al. Peroxisome proliferatoractivated receptor- $\gamma$ co-activator $1 \alpha$-mediated metabolic remodeling of skeletal myocytes mimics exercise training and reverses lipid-induced mitochondrial inefficiency. $J$ Biol Chem 2005; 280: 33588-33598.

11 Luquet S, Lopez-Soriano J, Holst D, et al. Peroxisome proliferator-activated receptor $\delta$ controls muscle development and oxidative capability. FASEB J 2003; 17: 2299-2301.

12 Puigserver P, Spiegelman BM. Peroxisome proliferatoractivated receptor- $\gamma$ coactivator $1 \alpha$ (PGC-1 $\alpha)$ : transcrip- tional coactivator and metabolic regulator. Endocr Rev 2003; 24: 78-90.

13 Daynes RA, Jones DC. Emerging roles of PPARs in inflammation and immunity. Nat Rev Immunol 2002; 2: 748-759.

14 Leeuwenberg JF, Jeunhomme TM, Buurman WA. Slow release of soluble TNF receptors by monocytes in vitro. $J$ Immunol 1994; 152: 4036-4043.

15 Schols AM, Wouters EF, Soeters PB, Westerterp KR. Body composition by bioelectrical-impedance analysis compared with deuterium dilution and skinfold anthropometry in patients with chronic obstructive pulmonary disease. Am J Clin Nutr 1991; 53: 421-424.

16 Steiner MC, Barton RL, Singh SJ, Morgan MD. Bedside methods versus dual energy X-ray absorptiometry for body composition measurement in COPD. Eur Respir J 2002; 19: 626-631.

17 Gosker HR, Schrauwen P, Broekhuizen R, et al. Exercise training restores uncoupling protein-3 content in limb muscles of patients with chronic obstructive pulmonary disease. Am J Physiol Endocrinol Metab 2006; 290: E976-E981.

18 Altman DG, Gore SM, Gardner MJ, Pocock SJ. Statistical guidelines for contributors to medical journals. BMJ (Clin Res Ed) 1983; 286: 1489-1493.

19 Gosker HR, Engelen MP, van Mameren H, et al. Muscle fiber type IIX atrophy is involved in the loss of fat-free mass in chronic obstructive pulmonary disease. Am J Clin Nutr 2002; 76: 113-119.

20 Gosker HR, Wouters EF, van der Vusse GJ, Schols AM. Skeletal muscle dysfunction in chronic obstructive pulmonary disease and chronic heart failure: underlying mechanisms and therapy perspectives. Am J Clin Nutr 2000; 71: 1033-1047.

21 Baar K. Involvement of $\operatorname{PPAR} \gamma$ co-activator-1, nuclear respiratory factors 1 and 2, and PPAR $\alpha$ in the adaptive response to endurance exercise. Proc Nutr Soc 2004; 63: 269-273.

22 Lin J, Wu H, Tarr PT, et al. Transcriptional co-activator PGC- $1 \alpha$ drives the formation of slow-twitch muscle fibres. Nature 2002; 418: 797-801.

23 Wang YX, Zhang CL, Yu RT, et al. Regulation of muscle fibre type and running endurance by PPAR $\delta$. PLOS Biol 2004; 2: e294.

24 Brun S, Carmona MC, Mampel T, et al. Activators of peroxisome proliferator-activated receptor $\alpha$ induce the expression of the uncoupling protein-3 gene in skeletal muscle: a potential mechanism for the lipid intakedependent activation of uncoupling protein-3 gene expression at birth. Diabetes 1999; 48: 1217-1222.

25 Schrauwen P, Mensink M, Schaart G, et al. Reduced skeletal muscle UCP3 protein content in pre-diabetic subjects and type 2 diabetic patients: restoration by rosiglitazone treatment. J Clin Endocrinol Metab 2006; 91: 1520-1525.

26 Hood DA. Invited review: contractile activity-induced mitochondrial biogenesis in skeletal muscle. J Appl Physiol 2001; 90: 1137-1157.

27 Garnier A, Fortin D, Delomenie C, Momken I, Veksler V, Ventura-Clapier R. Depressed mitochondrial transcription factors and oxidative capacity in rat failing cardiac and skeletal muscles. J Physiol 2003; 551: 491-501. 
28 Roden M. Muscle triglycerides and mitochondrial function: possible mechanisms for the development of type 2 diabetes. Int J Obes (Lond) 2005; 29: Suppl. 2, S111-S115.

29 Sekiguchi K, Tian Q, Ishiyama M, et al. Inhibition of PPAR- $\alpha$ activity in mice with cardiac-restricted expression of tumor necrosis factor: potential role of TGF- $\beta / S m a d 3$. Am J Physiol Heart Circ Physiol 2007; 292: H1443-H1451.

30 Russell AP, Feilchenfeldt J, Schreiber S, et al. Endurance training in humans leads to fibre type-specific increases in levels of peroxisome proliferator-activated receptor- $\gamma$ coactivator-1 and peroxisome proliferator-activated receptor- $\alpha$ in skeletal muscle. Diabetes 2003; 52: 2874-2881.

31 Watt MJ, Southgate RJ, Holmes AG, Febbraio MA. Suppression of plasma free fatty acids upregulates peroxisome proliferator-activated receptor (PPAR) $\alpha$ and $\delta$ and PPAR coactivator $1 \alpha$ in human skeletal muscle, but not lipid regulatory genes. J Mol Endocrinol 2004; 33: 533-544.

32 Russell AP, Hesselink MK, Lo SK, Schrauwen P. Regulation of metabolic transcriptional co-activators and transcription factors with acute exercise. FASEB J 2005; 19: 986-988.

33 Narravula S, Colgan SP. Hypoxia-inducible factor 1-mediated inhibition of peroxisome proliferator-activated receptor $\alpha$ expression during hypoxia. J Immunol 2001; 166 : 7543-7548.

34 Zhang B, Berger $\mathrm{J}, \mathrm{Hu} \mathrm{E}$, et al. Negative regulation of peroxisome proliferator-activated receptor- $\gamma$ gene expression contributes to the antiadipogenic effects of tumor necrosis factor- $\alpha$. Mol Endocrinol 1996; 10: 1457-1466.

35 Nystrom T, Nygren A, Sjoholm A. Increased levels of tumour necrosis factor- $\alpha$ in type 2 diabetic patients after myocardial infarction are related to endothelial dysfunction. Clin Sci (Lond) 2006; 110: 673-681. 